\title{
Editorial Núm. 19
}

\section{Editorials No 19}

\author{
Autora: \\ García Perea, Eva ${ }^{1}$
}

1. Facultad de Medicina. Universidad Autónoma de Madrid. España. ORCID: https://orcid.org/0000-00026972-3261. Correo electrónico: meva.garcia@uam.es

Palabras clave: poesía; pandemia; hoteles medicalizados; docencia universitaria; pacientes Covid.

Keywords: poetry; pandemic; medicalized hotels; university teaching; Covid patients.

Hace aproximadamente un año, el Consejo Ejecutivo de la OMS y el CIE, declararon el 2020 como el "Año Internacional de la Enfermería". El objetivo era impulsar y visibilizar a la Enfermería a nivel mundial, especialmente para solucionar el déficit global de enfermeras. A la par nace el movimiento Nursing Now (que tiene su origen en el Parlamento británico) y que en pocos meses se extiende por numerosos países, ciudades, y en el caso de España por muchas comunidades autónomas. Este movimiento abandera un informe, llamado "The Triple Impact", en el que se refleja (entre otros muchos puntos), que si se potencia e invierte en enfermería se obtienen tres resultados significativos: mejoras asistenciales en el cuidado del paciente y de la población que mejora la equidad de género y mejora la economía de los países.

Puede citar este artículo como: García Perea E. Editorial Núm. 19. RECIEN. Revista Científica de Enfermería. 2020; 19: 1-5. https://doi.org/10.14198/recien.2020.19.01 
Desde Nursing Now Comunidad de Madrid, eran numerosas las actividades que teníamos preparadas apoyando esta iniciativa: eventos, jornadas, simposios, entregas de premios, hasta una carrera popular "Corre con tu enfermera", con la que pensábamos llenar de "runners" las principales arterias de nuestra ciudad.

Pero la vida nos tenía preparado otro escenario para hacernos visibles en este 2020, un escenario especial, dramático y duro, en el que las enfermeras íbamos a poner en marcha la esencia de nuestra profesión: "cuidar y estar" con los pacientes y sus desamparadas familias.

Como enfermera docente, investigadora y gestora tengo grabado el día 18 de marzo en el que se me solicita como una orden de Estado, que facilite los contactos de nuestros estudiantes de Enfermería, porque se les necesitaba en los hospitales de nuestra ciudad, ante la avalancha de pacientes COVID-19.

A la vez que nuestros estudiantes, las profesoras del Departamento de Enfermería de la UAM nos pusimos a disposición de la Comunidad de Madrid para brindar apoyo telemático, consultas online, video consultas y atención telefónica a personas con sintomatología que estuviesen en casa y poder seguir su evolución o atender dudas de la población. Las profesoras que no estábamos en grupos de riesgo y podíamos conciliar nuestra vida familiar mejor, nos ofrecimos voluntarias para trabajar en los hoteles medicalizados que se empezaron a abrir por toda la ciudad.

Han sido numerosas las vivencias estos meses, y en estas líneas quiero contar el regalo que me ha dado la vida como enfermera asistencial. A mis estudiantes siempre les digo que la mayor gratitud y reconocimiento lo obtendrán de sus pacientes y este es un ejemplo. Mi querido amigo Fernando Beltrán (gran poeta y maravilloso ser humano), enfermó de Covid y estuve en contacto telefónico con él desde el inicio de su enfermedad, ingreso, alta y recuperación. Yo hacía una labor de apoyo, de información, tranquilizándole desde el móvil cuando estaba ingresado, intentando aplacar sus preocupaciones e incertidumbres. Cuando ya se encontraba bien, quedamos un día, en el cual me regaló y dedicó el poema que cito a continuación; "Tacto". 


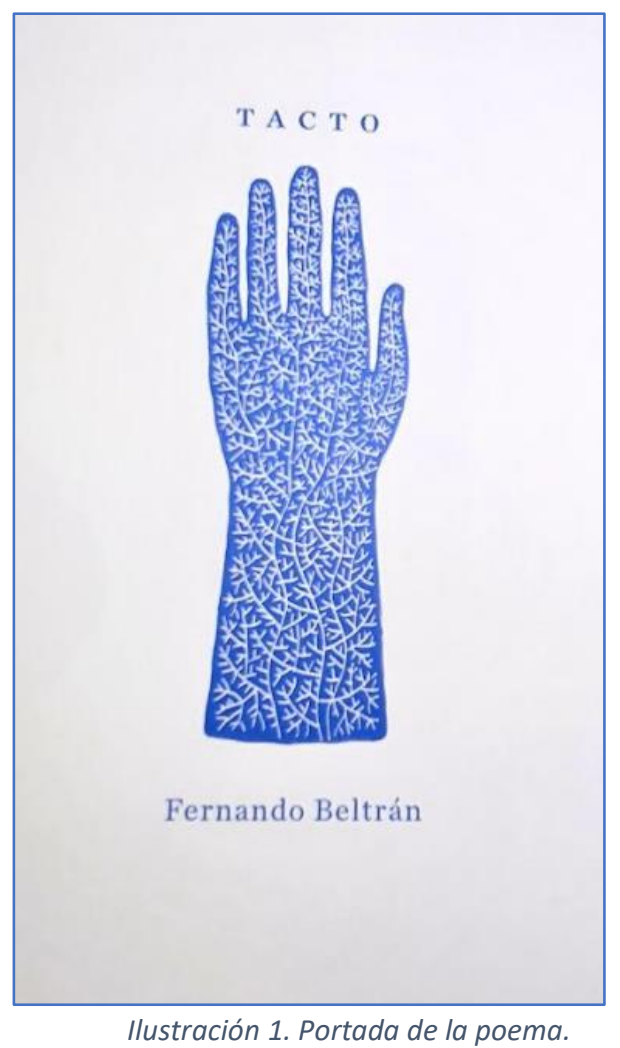

El poema nace cuando Fernando estaba ingresado en el hospital, con problemas respiratorios, musculares, profundo malestar y miedo, viendo a las enfermeras enfundadas en sus trajes de protección y sintiendo cómo le tocaban sólo cuando era preciso con unos "guantes azules". Este poema nos lo dedica a toda la Enfermería, por eso quiero que se disfrute de su lectura y se conozca.

Nada será como antes.

La lluvia no será ya la lluvia, será celebración aún más gozosa, mirarla cómo cae traerá un milagro de panes y de peces llegando desde el cielo para empujar la flor, el trigo, la memoria de tu cuerpo y mi cuerpo aquella tarde que fue todas las tardes.

Las cosas no serán la misma cosa, los árboles no serán ya los árboles, serán ahora un abrazo sin contagio al alcance de todos, descubrirás que su sombra es más sombra y que incluso en invierno, ya sin hojas, se ven todos los nidos con mayor nitidez, vacíos, pero intactos. 
Las cosas no serán la misma cosa, las calles no serán ya las calles, la alegre muchedumbre será ahora una extraña pasajera con su maleta a solas aconteciendo a un mundo que no entiende, y aunque la gente ocupe las aceras tú las verás vacías, y hacia dentro extraviadas quizás, preguntándote ellas cómo se llega a ti.

Las cosas no serán la misma cosa,

las ventanas no serán ya ventanas, las miradas no serán ya miradas, no habrá aplausos sin lágrimas, sin que llore mi cuerpo al recordar con hiel agradecida las manos que sin manos se acercaban a mí, no amaré ya jamás como allí amé el tacto de aquel guante con sus dedos de plástico.

Las cosas no serán la misma cosa, la piel no será ya la piel ni el desnudo el desnudo, habrá que comenzar a desvestirse por el botón del miedo, y al besarnos quitada ya la ropa, aprender que había huecos antes nunca tocados,

por fin seremos tacto,

recorrerá mi lengua muy despacio la isla abandonada, estallaremos juntos como si fuera un último deseo cumplido cuando ya no crees en nada.

Las cosas no serán la misma cosa,

nosotros no seremos los mismos, los otros no serán ya los otros, el amor no será ya el amor, será solo el amar, y será más.

No habrá piel, habrá carne jugándose la vida.

Madrid, 28 de abril a Eva García Perea. 
Queridas y queridos colegas, este año 2020, nos está brindado la oportunidad de que nuestra sociedad aprecie y reconozca nuestros conocimientos, formación y trabajo, por ello debemos seguir ofreciendo unos cuidados de excelencia a pacientes y familias. Estoy convencida de que si seguimos este camino seremos imparables y habremos salido fortalecidos como colectivo en esta terrible pandemia. 